\title{
Comparative Study between the Use of Topical Glyceryl Trinitrate Vs. Topical Diltiazem in Treatment of Acute Anal Fissure
}

\author{
HANY A. WASFY, M.Sc.; MOHAB G. ELBARBARY, M.D. and IBRAHIM M. ABDEL-MAKSOUD, M.D. \\ The Department of General Surgery, Faculty of Medicine, Ain Shams University
}

\begin{abstract}
Background: Acute anal fissure is a painful condition commonly results due to an increase in internal anal sphincter pressure. It is a painful condition which leads to significant morbidity mostly in young adults. It is a split in the mucosa of the distal anal canal that can progress to form a chronic linear ulcer. The common symptoms are severe pain on or after defecation and bleeding per anus.
\end{abstract}

Aim of Study: The main aim of this study is to evaluate the efficacy and adverse effects of topical 2\% Diltiazem ( Calcium channel blocker) and topical $0.2 \%$ Glyceryl trinitrate ( GTN), when administered as single agents in the treatment of acute anal fissure.

Patients and Methods: 40 Patients with acute anal fissure were enrolled in the study. They were randomized using a closed envelop technique into two group (20 patients each): Group A (2\% Diltiazem users), and Group B (0.2\% Glyceryl trinitrate users). Pain was evaluated using a pain Visual Analog Scale (VAS), we also evaluated the anal bleeding, constipation, perianal itching (anal pruritus) before, during and after the topical medications are used, and the results of each topical medications as healing, recurrence rates, onset of relief of symptoms, onset required to achieve complete healing, number and severity of side effects as (headache, postural hypotension, flushing, allergy, GIT upset) or ineffectiveness.

Results: Both $0.2 \%$ glyceryl trinitrate ointment and $2 \%$ diltiazem ointment are equally effective concerning pain relief, and recurrence rates, while higher healing rates with topical Diltiazem (DTZ) than topical Glyceryl Trinitrate (GTN) were recorded ( $85 \%$ compared to $75 \%$ respectively). However, headache is a troublesome side effect with topical glyceryl trinitrate. Accordingly, topical 2\% diltiazem is preferable as the treatment of choice for acute anal fissure.

Conclusion: Although surgical management like anal dilatation and open or closed sphincterotomy are a one-time solution with good symptomatic relief, it may be complicated by complications of wound healing, and permanent incontinence of flatus or faeces. The preferable treatment of acute anal fissure is becoming more medical since it is cost-effective. Both $0.2 \%$ glyceryl trinitrate ointment and $2 \%$ diltiazem ointment are equally effective in concerning pain relief, healing and recurrence rates. However, headache is a troublesome

Correspondence to: Dr. Hany A. Wasfy,

E-Mail: hany.wasfy@yahoo.com side effect in patients treated with topical glyceryl trinitrate. Therefore, when considering medical management for treating acute anal fissure, topical $2 \%$ diltiazem is the treatment of choice.

Key Words: Topical glyceryl trinitrate - Topical Diltiazem Acute anal fissure.

\section{Introduction}

ANAL fissure is a painful condition which causes significant morbidity mostly in young adults. It is a split in the mucosal layer of the distal anal canal that can progress to form a chronic linear ulcer. The classic symptoms are severe pain on or after defecation and bleeding per anus [1].

The main abnormality in fissure is the persistent increased tone of the Internal Anal Sphincter (IAS), increasing the Maximal Anal Resting Pressure ( MARP), and this can result from psychological stress [2].

Anal fissures are usually single, they usually lie on the posterior midline, and less commonly on the anterior midline in one tenth of cases [3].

The main cause of anal fissure is still unknown. Current theories suggest that it may be an ischemic ulcer. Sometimes, it is secondary to specific diseases, such as AIDS, Crohn's Disease, Ulcerative Colitis, syphilis, tuberculosis, or malignancy [4].

Glyceryl Trinitrate (GTN) is used for many years; Nitric oxide increases the perfusion to the affected area and decreases muscle tone of internal anal sphincter, on the other hand, Diltiazem is derived from benzothiozapine group; it causes vasodilataion and increases tissue perfusion. It is a calcium channel blocker which also decreases the resting tone of the muscle. Many recent studies showed that Diltiazem is very effective in treating patients with anal fissures that have not responded 
to GTN. Diltiazem has also shown to reduce the number of patients requiring surgery $[\mathbf{5 , 6 ]}$.

Conservative treatment is the first line of treatment for acute anal fissure. Chronic fissures do not respond to conservative treatment [7].

Surgical interventions, as, dermal advancement flap and autologous fat transplantation, anal stretch, posterior sphincterotomy, lateral internal sphincterotomy, fissurectomy are commonly associated with risk of a transient incontinence. Pharmacological agents, such as Glyceryl Trinitrate (GTN), Diltiazem (DTZ) and botulinum injection, can be successful treatments but they have a significant recurrence rate $[\mathbf{8 , 9}]$.

\section{Aim of the work:}

To compare between the effect and results of two different methods of chemical sphincterotomy ( Topical $0.2 \%$ Glyceryl Trinitrate (GTN) ointment, and Topical 2\% Diltiazem ointment (Calcium channel blocker) in the treatment of acute anal fissure with assessment of the effectiveness of both topical preparations as alternatives in the management of acute anal fissure.

\section{Patients and Methods}

This trial was designed as a prospective, randomized, double-blinded, controlled trial, a sample size of 40 patients with acute anal fissure presenting to our General Surgery Clinic of El-Demerdash University Hospital, Faculty of Medicine, Ain Shams University, between February and July 2020 were enrolled in the study, they were divided randomly using a closed envelop technique into 2 groups (20 patients each), informed consent and full medical history were obtained, anal examination was performed for all patients to exclude other pathologies. Most cases with an anal fissure do not tolerate a digital anoscope or digital rectal examination.

For examination, patient was placed in the left lateral decubitus position with knees bent toward the chest. (Suitable draping was used to keep the dignity of the patient and to minimize any embarrassment). Good lighting was essential.

Gentle retraction of the perianal skin usually allows visualization of the fissure directly.

\section{Our inclusion criteria were as follows:}

1- Patients had been experiencing acute anal fissure symptoms for less than 2 months (acute).

2- With the use of topical medications, all patients were advised to modify their diet (high fiber diet, and increase water intake daily to 2-3 liters a day.

3- Patient did not receive any previous topical medications for treatment of the acute anal fissure.

\section{Exclusion criteria for our study:}

Patients with history of migraine or severe headaches, pregnant or breast feeding women, patients on Nitrate treatment like ischemic heart patients, hypothyroidism (Hypothyroidism were recorded as a side effect in some patients on Nitrate treatment), patients that had recently head injuries ( due to nitrates and $\mathrm{Ca}$ channel blockers vasodilatation effect that can exacerbate the condition), patients with COPD (Ca channel blockers causes cough). Patients that had recently heart attack ( angina pectoris) as $\mathrm{Ca}$ channel blockers and nitrates may lead to brady or tachycardia and their vasodilatation effect.

Patients were randomized into two groups:

- Group A (2\% Diltiazem users).

- Group B (0.2\% glyceryl trinitrate users).

Ages, genders, physical examination and anal examination results, symptoms prior to and after treatment (pain, straining during defecation), whether or not fissure improved after treatment, and complications caused by treatment were recorded.

Patients in Group A were asked to apply $2 \%$ Diltiazem ointment (a pea-or chickpea-sized amount; approximately $1 \mathrm{~g}$ ) twice daily to the anodermal area for a period of 8 weeks. Patients in Group B were asked to apply a $0.2 \%$ Glyceryl trinitrate ointment (a pea-or chickpea-sized amount; approximately $1 \mathrm{~g}$ ) to the anodermal area, twice daily for 8 weeks. Patients in each group were advised to consume fiber-rich diet and increase water intake daily to 2-3 liters a day.

All patients presented to our clinic weekly for 8 weeks (duration of treatment) then weekly for other 4 months for follow-up and assessment of relief of symptoms, healing, recurrence rates, and side effects of our both topical medications as ( headache, postural hypotension, allergic reaction, GIT upset and ineffectiveness). We assessed the pain using a Visual Analog Scale (VAS).

\section{Statistical analysis:}

Data were collected, revised, coded and entered to the Statistical Package for Social Science (IBM SPSS) version 23 . So, the $p$-value was considered

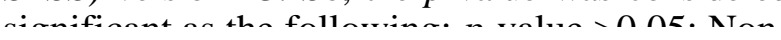


significant (NS), $p$-value <0.05: Significant (S), $p$-value <0.01: Highly significant (HS).

\section{Results}

Table (1): Comparison between patients in groups A and B regarding gender, site, number of fissures and.

\begin{tabular}{|c|c|c|c|c|}
\hline & $\begin{array}{c}\text { Group A } \\
\text { No. }=20\end{array}$ & $\begin{array}{c}\text { Group B } \\
\text { No. }=20\end{array}$ & $\begin{array}{c}\text { Test } \\
\text { value }\end{array}$ & $\underset{\text { value }}{p-\mathrm{S} \text { ig }}$ \\
\hline \multicolumn{5}{|l|}{ Gender: } \\
\hline Females & $11(55.0 \%)$ & $8 \quad(40.0 \%)$ & $0.902 *$ & $0.342 \mathrm{NS}$ \\
\hline Males & $9 \quad(45.0 \%)$ & $12(60.0 \%)$ & & \\
\hline \multicolumn{5}{|l|}{ Anterior fissure: } \\
\hline No & $18(90.0 \%)$ & $20(100.0 \%)$ & $2.105^{*}$ & $0.147 \mathrm{NS}$ \\
\hline Yes & $2(10.0 \%)$ & $0 \quad(0.0 \%)$ & & \\
\hline \multicolumn{5}{|l|}{ Posterior fissure: } \\
\hline No & $2(10.0 \%)$ & $0 \quad(0.0 \%)$ & $2.105^{*}$ & $0.147 \mathrm{NS}$ \\
\hline Yes & $18(90.0 \%)$ & $20(100.0 \%)$ & & \\
\hline \multicolumn{5}{|l|}{ Number of fissure: } \\
\hline Single & $18(90.0 \%)$ & $20(100.0 \%)$ & $2.105^{*}$ & $0.147 \mathrm{NS}$ \\
\hline Multi & $2(10.0 \%)$ & $0 \quad(0.0 \%)$ & & \\
\hline \multicolumn{5}{|l|}{ Before treatment } \\
\hline \multicolumn{5}{|l|}{ Anal bleeding: } \\
\hline No & $6 \quad(30.0 \%)$ & $6 \quad(30.0 \%)$ & $1.037 *$ & $0.595 \mathrm{NS}$ \\
\hline Mild & $13(65.0 \%)$ & $14(70.0 \%)$ & & \\
\hline Moderate & $1(5.0 \%)$ & $0 \quad(0.0 \%)$ & & \\
\hline \multicolumn{5}{|c|}{ Peri-anal pruritus: } \\
\hline No & $6 \quad(30.0 \%)$ & $13(65.0 \%)$ & $4.912 *$ & $0.027 \mathrm{~S}$ \\
\hline Yes & $14(70.0 \%)$ & $7 \quad(35.0 \%)$ & & \\
\hline \multicolumn{5}{|c|}{$\begin{array}{l}\text { Current constipation } \\
\text { due to pain (fear of } \\
\text { defecation): }\end{array}$} \\
\hline No & $0 \quad(0.0 \%)$ & $0 \quad(0.0 \%)$ & NA & NA NA \\
\hline Yes & $20(100.0 \%)$ & $20(100.0 \%)$ & & \\
\hline \multicolumn{5}{|l|}{$\begin{array}{l}\text { Anal pain on pain } \\
\text { score: }\end{array}$} \\
\hline Median (IQR) & $7(7-8)$ & $8(7-9)$ & 2.092\# & $0.036 \mathrm{~S}$ \\
\hline Mean \pm SD & $7.20 \pm 0.89$ & $7.90 \pm 0.85$ & & \\
\hline Range & $5-8$ & $7-9$ & & \\
\hline $\begin{array}{l}p>0.05: \text { Non sign } \\
p<0.05: \text { Significa } \\
p<0.01: \text { Highly s }\end{array}$ & ficant. & $\begin{array}{l}\text { Chi-square } \\
\text { : Mann-Whit }\end{array}$ & $\begin{array}{l}\text { test. } \\
\text { ney test. }\end{array}$ & \\
\hline
\end{tabular}

The previous table shows that there was no statistically significant difference found between groups A and B regarding anal bleeding, while there was statistically significant increase in the incidence of anal pruritus in group A than group $\mathrm{B}$ with $p$-value $=0.027$ also significantly higher anal pain on pain score in group B than group A with $p$-value $=0.036$.

The previous table shows that there was no statistically significant difference found between group A and group B regarding gender of the studied cases, site of fissure and number of fissure with $p$-value $=0.342,0.147,0.311$ and 0.072 respectively.
Table (2): Comparison between groups A and B regarding healing, relief of symptoms, signs and developing signs of chronicity after 8 weeks of using our topical treatments.

\begin{tabular}{|c|c|c|c|c|c|}
\hline $\begin{array}{l}\text { After } 8 \text { weeks } \\
\text { of treatment }\end{array}$ & $\begin{array}{c}\text { Group A } \\
\text { No. }=20\end{array}$ & $\begin{array}{l}\text { Group B } \\
\text { No.=20 }\end{array}$ & $\begin{array}{l}\text { Test } \\
\text { value }\end{array}$ & $\begin{array}{c}p-s \\
\text { value }\end{array}$ & g. \\
\hline \multicolumn{6}{|l|}{ Complete healing: } \\
\hline No & $5 \quad(25.0 \%)$ & $3(15.0 \%)$ & $0.625 *$ & 0.429 & NS \\
\hline Yes & $15(75.0 \%)$ & $17(85.0 \%)$ & & & \\
\hline \multicolumn{6}{|l|}{ Fibrosis: } \\
\hline No & $17(85.0 \%)$ & $15(75.0 \%)$ & $0.625 *$ & 0.429 & NS \\
\hline Yes & $3 \quad(15.0 \%)$ & $5 \quad(25.0 \%)$ & & & \\
\hline \multicolumn{6}{|l|}{$\begin{array}{l}\text { No response to } \\
\text { treatment: }\end{array}$} \\
\hline No & $17(85.0 \%)$ & $15(75.0 \%)$ & $0.625 *$ & 0.429 & NS \\
\hline Yes & $3 \quad(15.0 \%)$ & $5 \quad(25.0 \%)$ & & & \\
\hline \multicolumn{6}{|l|}{ Skin tag: } \\
\hline No & $17(85.0 \%)$ & $15(75.0 \%)$ & $0.625 *$ & 0.429 & NS \\
\hline Yes & $3(15.0 \%)$ & $5 \quad(25.0 \%)$ & & & \\
\hline \multicolumn{6}{|l|}{ Anal bleeding: } \\
\hline No & $20(100.0 \%)$ & $20(100.0 \%)$ & NA & NA & NA \\
\hline Yes & $0 \quad(0.0 \%)$ & $0 \quad(0.0 \%)$ & & & \\
\hline \multicolumn{6}{|l|}{ Anal pruritus: } \\
\hline No & $20(100.0 \%)$ & $20(100.0 \%)$ & NA & NA & NA \\
\hline Yes & $0 \quad(0.0 \%)$ & $0 \quad(0.0 \%)$ & & & \\
\hline \multicolumn{6}{|l|}{ Constipation: } \\
\hline No & $20(100.0 \%)$ & $20(100.0 \%)$ & NA & NA & NA \\
\hline Yes & $0 \quad(0.0 \%)$ & $0 \quad(0.0 \%)$ & & & \\
\hline \multicolumn{6}{|l|}{ Anal pain score: } \\
\hline Median (IQR) & $0(0-0)$ & $0(0-1)$ & -0.794 & 0.427 & NS \\
\hline Mean \pm SD & $0.5 \pm 1.32$ & $0.85 \pm 1.6$ & & & \\
\hline Range & $0-5$ & $0-5$ & & & \\
\hline
\end{tabular}

*: Chi-square test.

The table shows statistically significant difference between Groups A and B regarding complete healing, fibrosis and developing a skin tag with a $p$-value of $0.429,0.429$ and 0.429 respectively. The table also shows no differences between both groups A and B concerning treatment ineffectiveness, anal bleeding, pruritus, constipation due to fear of painful defecation, anal pain on pain score respectively.

Table (1): Comparison between both Groups A and B regarding developing side effects during and after the use of our topical medications.

\begin{tabular}{|c|c|c|c|c|}
\hline Side effect & $\begin{array}{c}\text { Group A } \\
\text { No. }=20\end{array}$ & $\begin{array}{l}\text { Group B } \\
\text { No. }=20\end{array}$ & $\begin{array}{c}\text { Test } \\
\text { value }\end{array}$ & $\begin{array}{l}p-S i g \\
\text { value }\end{array}$ \\
\hline \multicolumn{5}{|c|}{ Postural hypotension: } \\
\hline No & $18(90.0 \%)$ & $13(65.0 \%)$ & $3.584 *$ & $0.058 \mathrm{NS}$ \\
\hline Yes & $2(10.0 \%)$ & $7(35.0 \%)$ & & \\
\hline \multicolumn{5}{|l|}{ Headache: } \\
\hline No & $18(90.0 \%)$ & $13(65.0 \%)$ & $3.584 *$ & $0.058 \mathrm{NS}$ \\
\hline Yes & $2(10.0 \%)$ & $7(35.0 \%)$ & & \\
\hline \multicolumn{5}{|l|}{ Flushing: } \\
\hline No & $18(90.0 \%)$ & $10(50.0 \%)$ & $7.619^{*}$ & $0.006 \mathrm{HS}$ \\
\hline Yes & $2(10.0 \%)$ & $10(50.0 \%)$ & & \\
\hline \multicolumn{5}{|l|}{ Allergy: } \\
\hline No & $20(100.0 \%)$ & $20(100.0 \%)$ & NA & NA NA \\
\hline Yes & $\begin{array}{ll}0 & (0.0 \%)\end{array}$ & $0(0.0 \%)$ & & \\
\hline \multicolumn{5}{|c|}{ Ineffectiveness: } \\
\hline No & $17(85.0 \%)$ & $15(75.0 \%)$ & $0.625^{*}$ & $0.429 \mathrm{NS}$ \\
\hline Yes & $3(15.0 \%)$ & $5(25.0 \%)$ & & \\
\hline \multicolumn{5}{|c|}{ Gastrointestinal upset: } \\
\hline No & $20(100.0 \%)$ & $20(100.0 \%)$ & NA & NA NA \\
\hline Yes & $\begin{array}{ll}0 & (0.0 \%)\end{array}$ & $0(0.0 \%)$ & & \\
\hline
\end{tabular}


The table shows statistically highly significant increase in group B than Group A regarding Flushing with a $p$-value of 0.006 . It also shows statistically no significant differences between group A and $\mathrm{B}$ regarding postural hypotension, headache and ineffectiveness with $p$-value $0.058,0.058$ and 0 . 429 respectively.

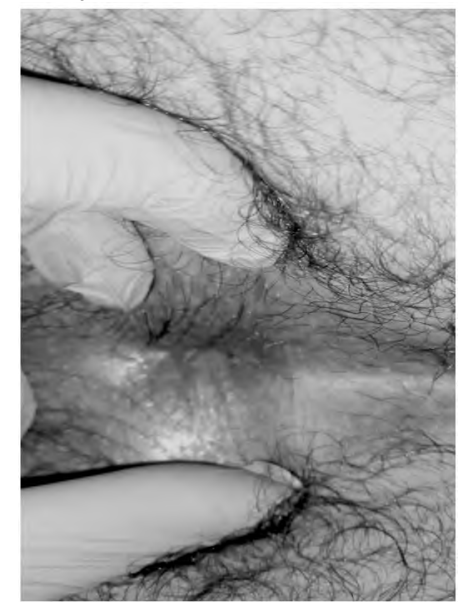

Fig. (1): Show case of acute anal fissure before and after treatment with GTN.

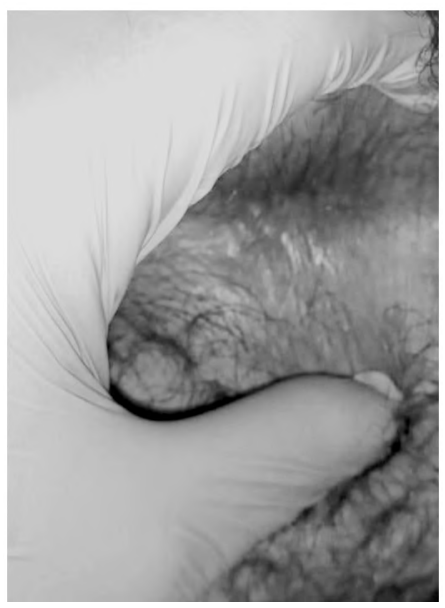

Fig. (2): Show case of acute anal fissure before and after treatment with diltiazem.

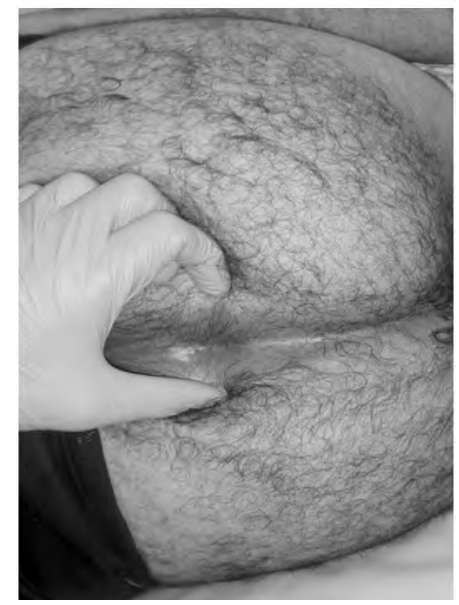

Fig. (3): Show case of acute anal fissure before and after treatment with GTN.

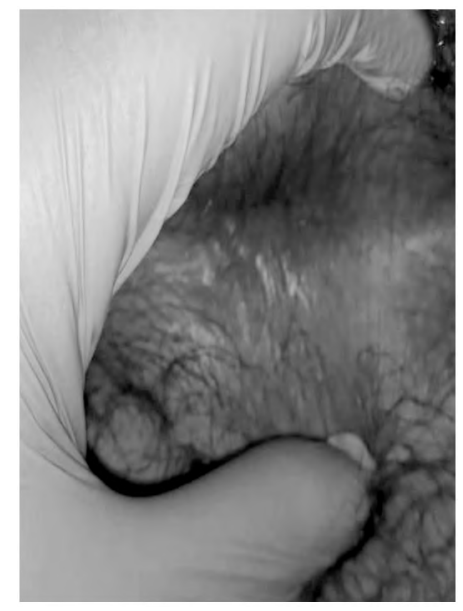

Fig. (4): Show case of acute anal fissure before and after treatment with diltiazem.

\section{Discussion}

Anal fissure is a painful condition that leads to significant morbidity in young adults. It is a split in the mucosal layer of the distal anal canal that forms a chronic linear ulcer. The common symptoms are severe pain on or after defecation and bleeding per Anus [1].

Pain during defecation, remaining for few minutes to many hours is suggestive of fissure-in-ano until proved otherwise. The diagnosis is established by simple medical examination.

It is classified due to duration of symptoms into: Acute, or chronic. Anal fissure for more than 2 months were classified as chronic anal fissure [10].

In many studies, $90 \%$ of cases, the fissures were located in posterior midline; but, in 10-20\% of females and $1-10 \%$ of males fissures were located in anterior midline. In our study, most of cases had fissures in posterior midline.

Many theories and studies correlated the cause of delayed healing of anal fissure or turning into chronic, to the increased intra-anal pressure due to many factors as:

(Persistent internal anal sphincteric contraction and chronic constipation), and this leads subsequently to decreased blood flow (Ischemia) to the ulcer (anal fissure) so leads to delayed healing, so to enhance and fasten the healing process for the anal fissure, the intra-anal pressure must be decreased either:

1- Surgically by lateral internal anal sphincterotomy, or doing the same internal anal sphincterotomy using laser, or 
2- Chemically by chemical internal anal sphincterotomy using topical medications intra-anally that relaxes the internal anal sphincter and decreases the intra-anal pressure, so improves the blood flow to the fissure site, so enhances healing, and may even prevent recurrence of the fissure.

New methods for chemical sphincterotomy has lately developed new medications, medications either to be topically applied like: (Topical GTN or calcium channel blockers e.g, nifedipine or Diltiazem) or in injection form as neurotoxins like Botulinum toxins.

In our study we used the safest, non-invasive technique, with the least complications reported, and with no fear of post-treatment incontinence, which is the topical medications, that should be applied intra-anally twice a day, for a 8 weeks period, followed by 4 months follow-up, to detect and record any side effects, complications, ineffectiveness, healing and recurrence rates.

In our clinical trial, no patients dropped out of the study, or were lost to the follow-up monitoring during the study, the trial was made on 40 patients, that were randomly chosen and divided into two groups with a closed envelop technique, each group consists of 20 patient, Group A used the topical 0. $2 \%$ Diltiazem (DTZ) ointment, while group B used topical 2\% Glyceryl trinitrate (GTN) ointment.

The mean age of patients in this study was 30.3 years in group A, and 30.4 years in group B; this correlates with other studies, suggestive of prevalence of the disease in young adults.

A number of 28 out of 40 patients in our trial presented with bleeding per rectum, with a percentage of $70 \%$ of patients in group $\mathrm{A}$ and $70 \%$ in group B.

While perianal itching (Pruritus) was present in 21 patients in both groups before starting our experiment, divided as follows $(70 \%$ of patients in group A, and $35 \%$ of patients in group B) patients with acute fissure in ano.

On the other hand, in our clinical trial, we recommended the patients to modify their diet to a high fiber diet in 40 out of 40 patients (100\%), and to do a hip bath with warm water after defecation also in $100 \%$ of patients in both groups, we also had to prescribe oral analgesics (paramol) to be taken during sharp pain attacks with a maximum dose of 1 tablet 3 times a day if needed, and 19 out of 20 patients $(95 \%)$ in group A, and 20 out of
20 patients $(100 \%)$ in group B used it, oral laxative tablets (Laxin tablets, only a tablet when needed with a maximum dose of 1 tablet 3 times a day) were also prescribed in the beginning of the trial to help patients overcome fear of defecation due to pain, and it was used by 8 out of 20 patients ( $40 \%$ ) in group A, and 8 out of 20 patients (40\%) in group B.

In our study, 17 out of 20 patients $(85 \%)$ had a mean pain score reduced gradually from an initial value of $8-6$ at 2 weeks, 2 at 4 weeks, and 0 at 8 weeks following treatment with DTZ, while in the other group treated with GTN, pain gradually decreased in 15 out of 20 patients $(75 \%)$ from an initial value of 9-6 at 2 weeks, and 0 at 8 weeks, the remaining 3 patients (15\%) in DTZ (Group A) turned chronic fissure with chronic anal pain with a value of $3-5$ at 8 weeks, and the remaining 5 patients (25\%) in GTN (Group B) turned into having chronic pain ranging from 3-5 on pain scale.

There was almost equally marked pain relief after using GTN (Glyceryl Trinitrate) and DTZ ( Diltiazem) ointments. The frequency of complete relief of symptoms compared between the two groups was not significant. However, the time taken for complete relief of symptoms in the GTN group was significantly less (4 weeks) than that in DTZ group. The mean time taken for healing for the DTZ group was $5.58 \pm 2.01$ weeks compared to the GTN group which was $4.85 \pm 1.84$ weeks. This shows that GTN achieves early healing (less time but not more healing rates) in comparison to DTZ. Complete healing and relief of symptoms was observed in $85 \%$ and $75 \%$ of patients in groups A (Diltiazem) and B (GTN) respectively. Ultimately, $85 \%$ of the anal fissures healed with DTZ ointment and $75 \%$ of fissures healed with GTN ointment, while remaining cases turned chronic.

The incidence of headaches, and postural hypotension reported with GTN was comparably higher (35\%) compared to DTZ (10\%).

There were no allergy, or gastrointestinal symptoms (GIT upset) from both medications reported, a randomized clinical comparative study between topical $0.2 \%$ GTN and 2\% diltiazem done by Pardhan et al. [12], at Agha Khan University Hospital, in Pakistan, included 60 adult patients with anal fissure, who were equally randomized to either topical $0.2 \%$ GTN or topical $2 \%$ Diltiazem for a period of two weeks, showed that patients who used topical Diltiazem reported more symptomatic relief than GTN and most common side effect in 
so this trial proved that chemical sphincterotomy with topical Diltiazem is more effective first line of treatment for early symptomatic relief of anal fissures, owing to negligible side effects.

As mentioned in the prospective randomized trial made by Bansal et al., [13] to compare and evaluate results and complications of topical $0.2 \%$ GTN vs. $2 \%$ Diltiazem, a total of 50 patients randomly assigned to 2 groups of 25 patients each, all of whom were treated with topical medications, Group A used topical $0.2 \%$ GTN and Group B used $2 \%$ diltiazem, for 6 weeks period, it showed that both topical preparations are equally effective in treatment of anal fissure, in terms of symptomatic pain relief, healing and recurrence, but headache is a troublesome side effect in patients treated with GTN, so this study recommended, when considering medical management of anal fissure, so $2 \%$ Diltiazem is preferable as first-line treatment.

In another randomized clinical trial, carried out by Sajid et al., [9] investigating the effectiveness of topical 2\% Diltiazem and topical $0.2 \%$ GTN, that included a 481 patients, where a 238 patients were treated with topical Diltiazem, and the other 243 patients were treated with a topical GTN, it was found that Diltiazem was associated with lower incidence of Recurrence and side effects (Headache), accordingly this study recommends Diltiazem as preferred first line of treatment in anal fissures, this study supports the superiority of Diltiazem over GTN for anal fissure.

On the other hand, another clinical study, carried out by Madhu [14] to compare between the topical 0 . $2 \%$ GTN vs. $2 \%$ Diltiazem on 231 patients with anal fissure, where 118 patients received topical Diltiazem and the other 113 patients used topical Glyceryl trinitrate (GTN) for 6 weeks, and this study showed that both topical medications were effective in treatment of anal fissure, but Diltiazem is preferred to GTN due to its lesser side effects and long term better control.

In contrast to other studies, we had no reported cases of recurrent anal fissure, while $25 \%$ recurrence rate with GTN was reported in a study made by Puche et al., [15] due to a long period of his clinical trial that extended to 25 months, so further follow-up for patients is mandatory for possible late recurrence detection. On the other, the prospective randomized study made by Bansal et al., [ 13] showed higher recurrence rate of fissure in the same site in 3 out of 20 patients $(15 \%)$ treated with topical $2 \%$ diltiazem more than the group of patients treated with topical $0.2 \%$ GTN where 2 out of 18 patients $(11.1 \%)$ had recurrence.
On the contrary, a systemic review on seven trials done by Sajid et al., [9] showed that patients treated with topical Diltiazem showed lower recurrence rates than that with GTN.

\section{Conclusion:}

Although surgical techniques like lateral internal sphincterotomy may be a one-time solution with good symptomatic relief, it can be complicated by non-healing wounds and permanent incontinence of flatus or faeces. The treatment of acute anal fissure nowadays is becoming increasingly medical since it is cost-effective and, moreover, incurs no loss of man hours.

The results of the our study demonstrate that both $0.2 \%$ glyceryl trinitrate ointment and $2 \%$ diltiazem ointment are equally effective in terms of symptomatic pain relief, healing and recurrence in the treatment of acute anal fissure. However, headache may be a troublesome side effect in patients treated with glyceryl trinitrate ointment. Therefore, $2 \%$ diltiazem ointment may be preferable as first-line treatment of acute anal fissure.

\section{References}

1- STEWART D.B., GAERTNER W., GLASGOW S., MIGALY J., FEINGOLD D. and STEELE S.R.: Clinical practice guideline for the management of anal fissures. Diseases of the Colon \& Rectum., 60 (1): 7-14, 2017.

2- BARNES T.G., ZAFRANI Z. and ABDELRAZEQ A.S.: Fissurectomy combined with high-dose botulinum toxin is a safe and effective treatment for chronic anal fissure and a promising alternative to surgical sphincterotomy. Diseases of the Colon \& Rectum., 58 (10): 967-73, 2015.

3- BANSAL A.R., YADAV P., JENA S. and KUMAR S.: Comparative evaluation of fissurectomy versus lateral internal sphincterotomy in the treatment of chronic anal fissure. International Surgery Journal, 5 (4): 1407-10, 2018.

4- GLOVER P.H., TANG S.J., WHATLEY J.Z., DAVIS E. D., JEX K.T., WU R. and LAHR C.J.: High-dose circumferential chemodenervation of the internal anal sphincter: A new treatment modality for uncomplicated chronic anal fissure: A retrospective cohort study (with video). International Journal of Surgery, 23: 1-4, 2015.

5- BIELECKI K., KOLODZIEJCZAK M. and WI ACZEK A. : Comparative assessment of effectiveness of combination therapy with $7 \%$ Sucralfate and $2 \%$ Diltiazem versus $2 \%$ Diltiazem alone in treatment of chronic anal fissurerandomized prospective study. Nowa Medycyna, 2013.

6- MALIK F., ALI N., JAFRI S.I., NAGLAK M., SUNDERMEYER M. and PICKENS P.V.: Analysis of efficacy and tolerability of Bruton tyrosine kinase inhibitor ibrutinib in various B-cell malignancies in the general 
7- EMILE S.H.: Indications and technical aspects of internal anal sphincterotomy: Highlighting the controversies. Diseases of the Colon \& Rectum., 60 (1): 128-32, 2017.

8- GAGLIARDI G., PASCARIELLO A., ALTOMARE D.F., ARCANÀ F., CAFARO D., La TORRE F., De NARDI P., BASSO L., De STEFANO I., GRECO V.J. and VASAPOLLO L.: Optimal treatment duration of glyceryl trinitrate for chronic anal fissure: Results of a prospective randomized multicenter trial. Techniques in Coloproctology, 14 (3): 241-8, 2010.

9- SAJID M.S., WHITEHOUSE P.A., SAINS P. and BAIG M. $\mathrm{K}$ : "Systematic review of the use of topical diltiazem compared with glyceryltrinitrate for the nonoperative management of chronic anal fissure". Colorectal Disease, 15 (1): 19-26, 2013.

10- GARRIDO R., NESTOR L., KARINNA L., MARIO A., GUNTHER B., ALDO C. and HECTOR C.: "Gonyautoxin: New treatment for healing acute and chronic anal fissures." Diseases of the Colon \& Rectum., 48 (2): 335 43, 2005. treatment of chronic fissure-in-ano. Diseases of the Colon\& Rectum., 40 (11): 1318-20, 1997.

12- PARDHAN A., RIZWAN A., SAMIA M. and GHULAM M.: "Diltiazem vs. glyceryl tri-nitrate for symptomatic relief in anal fissure: A randomised clnical study". J. Pak. Med. Assoc., 64 (5): 510-3, 2014.

13- BANSAL A.R., PAWAN K.Y., RAJESH G., NARESH P. and RATHINDRA T.: "Comparative evaluation of $0.2 \%$ glyceryl trinitrate vs. $2 \%$ diltiazem ointment in treatment of chronic anal fissure treatment-a randomized trial". Hellenic Journal of Surgery, 88 (1): 25-30, 2016

14- MADHU L.: Study on use of topical Diltiazem versus topical glyceryl trinitrate (GTN) in the treatment of chronic anal fissure: A retrospective study. "Journal of Evolution of Medical and Dental Sciences, 3 (54): 12418, 2014

15- PUCHE J.J., JOSÉ M.G., FRANCISCO L.V., ISMAIL A. M. and JOSÉ V.R.: "Local treatment of a chronic anal fissure with diltiazem vs. nitroglycerin. A comparative

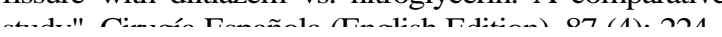




\section{دراسة مقارثية بين إستخدام الجلسريل ثلاثى النترات

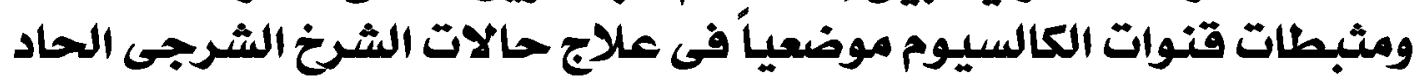

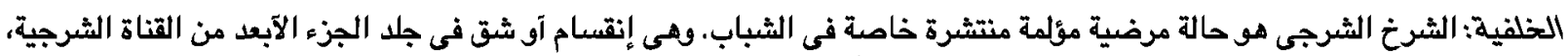

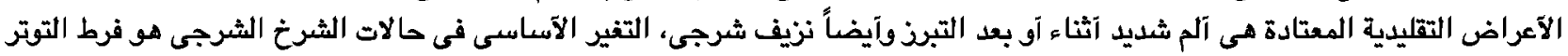

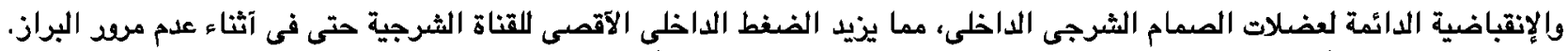

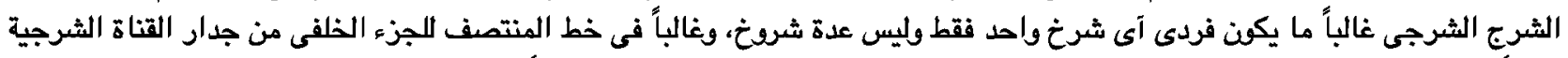

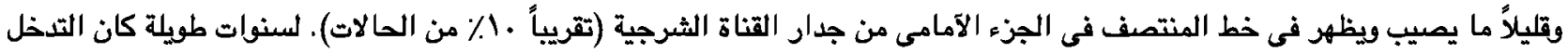

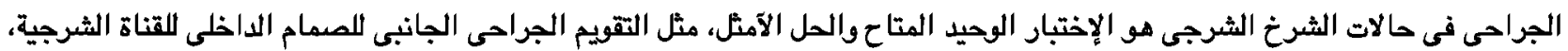

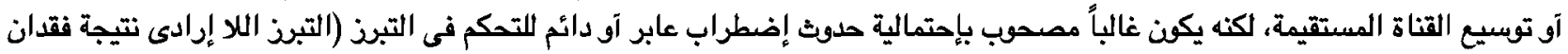

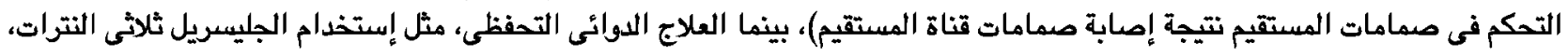

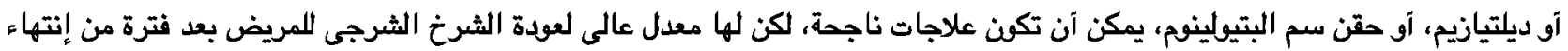

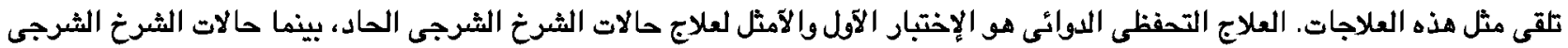
المزمن لا تستجيب العلاج التحفظى.

الهدف من الدراسة: هدف هذا البحث هو المقارنة بين تآثير ونتائج إستعمال دوائين مختلفين كدهانات موضعية (جلسريل ثاثلاثى النترات

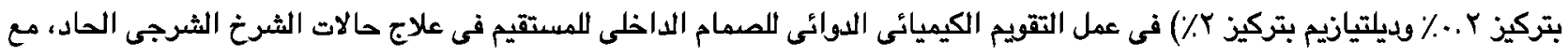

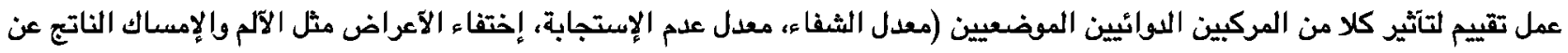

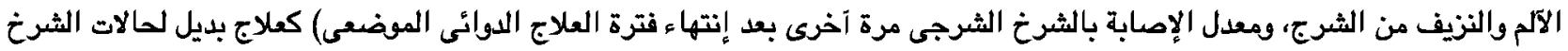

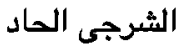

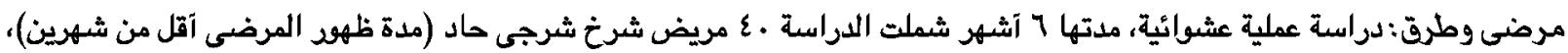

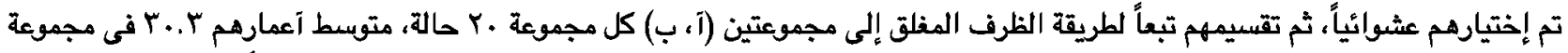

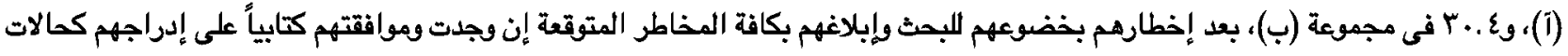

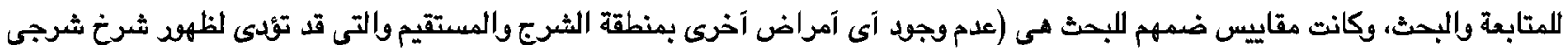

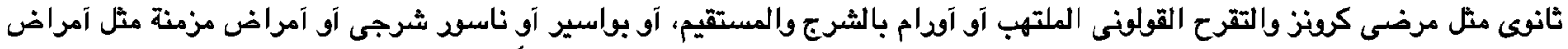

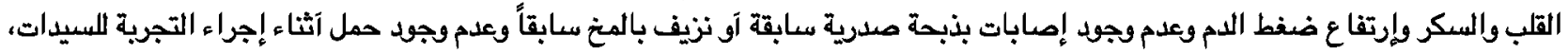

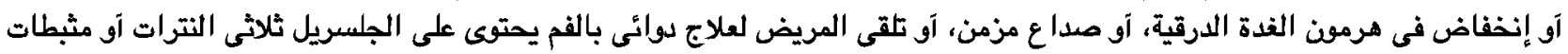

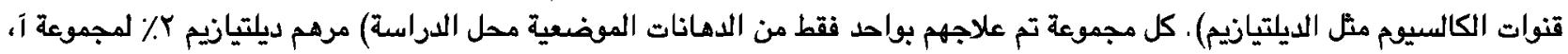

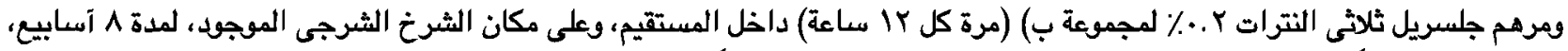

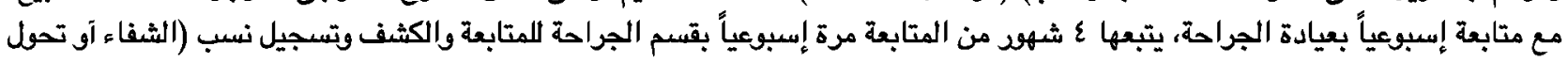

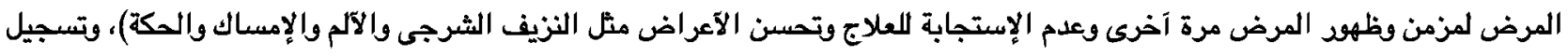

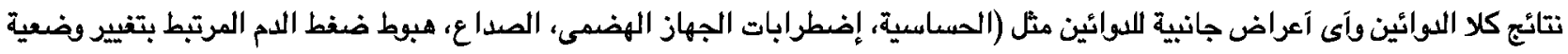

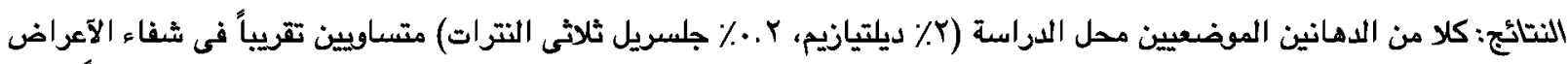

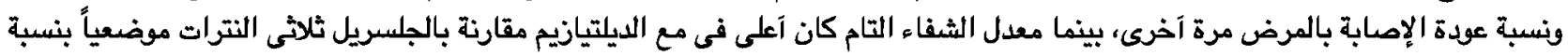

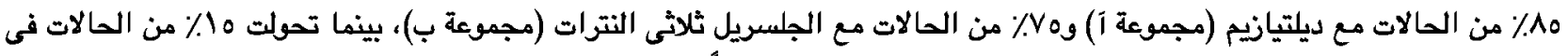

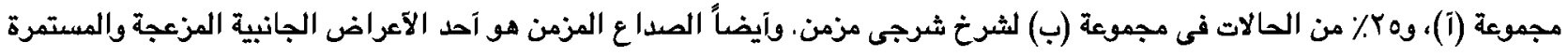

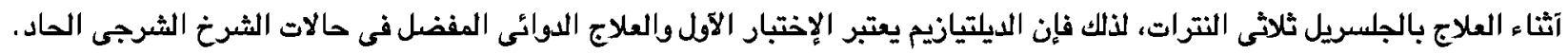

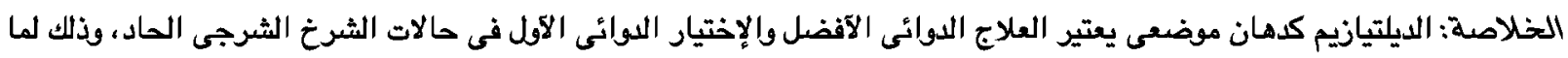
اله من نسب شفاء آعلى فآعراض جانبية آقل من الدهان الموضعى البديل (الجلسريل ثلاثى النترات). 